\title{
Capacitance and Surface of Carbons in Supercapacitors
}

\author{
Belén Lobato, Loreto Suárez, Laura Guardia, Teresa A. Centeno* \\ Instituto Nacional del Carbón (INCAR-CSIC). Francisco Pintado Fe, 26. 33011 Oviedo
}

(Spain)

\begin{abstract}
This research is focused in the missing link between the specific surface area of carbons surface and their electrochemical capacitance. Current protocols used for the characterization of carbons applied in supercapacitors electrodes induce inconsistencies in the values of the interfacial capacitance (in $\mathrm{F} \mathrm{m}^{-2}$ ), which is hindering the optimization of supercapacitors. The constraints of both the physisorption of $\mathrm{N}_{2}$ at $77 \mathrm{~K}$ and the standard methods used for the isotherm analysis frequently lead to a misleading picture of the porosity. Moreover, the specific surface area of carbons loses their meaning when the supercapacitor operates with organic electrolytes and ionic liquids and the actual surface involved in charge storage has to be assessed by molecular probes suiting the critical dimensions of the ions. In the case of certain carbons such as graphene type-materials, the voltage-driven mechanism may facilitate the access of electrolyte ions to spaces between carbon layers, providing a larger area than that estimated by gas adsorption. Finally, the morphological and porous features of carbons can be extremely modified when they are processed in electrodes. Due to their impact, all these issues should not be neglected and the characterization protocols must be adapted for this specific application of carbons.
\end{abstract}

\footnotetext{
*Corresponding author. Tel:+34 985118968. E-mail: teresa@incar.csic.es (Teresa A. Centeno)
} 


\section{Introduction}

The great technological implementation of nanoporous carbons stems from the opportunity to be produced with a tailored porosity in a variety of configurations. They are found as powders, fibers, foams, cloths, monoliths, etc. and as a result of their wide spectrum of porous features are able to suit multiple applications in very diverse industrial processes. For many years, they have acted as purification filters, adsorbents for emissions control, catalyst supports, host matrices for active materials, etc. [1]. In the last two decades, nanoporous carbons have also found a niche in electrical energy storage as electrodes in electrochemical double-layer capacitors, EDLC (also known as supercapacitors, SC) [2,3].

All these applications correspond to very different processes but their description essentially relies on porosity parameters such as pore volume, specific surface area and pore-size distribution. It follows that the standard textural characterization of carbons for adsorption or catalysis is also applied when they are used in EDLC systems.

The porosity of carbons is generally assessed by the determination of the adsorption isotherm (amount of gas adsorbed at increasing relative pressure and constant temperature) of small molecules such as $\mathrm{N}_{2}, \mathrm{CO}_{2}$, Ar, etc. There are different methods for analyzing the corresponding isotherms which provide the specific surface area as well as other porous features responsible for their performance [3-6].

In carbon-based SC, electrical energy storage takes place through the electroadsorption of electrolyte ions at the surface of charged carbon electrodes. This mechanism implies that the capacitance (C) is proportional to the extent of the electrochemical double-layer (S) and to the relative permittivity of the solution $(\varepsilon)$ and reciprocally dependent on the charges separation (d)

$$
C=\frac{\varepsilon S}{d}
$$

Following the simplest approach from Eq. 1, the capacitance is expected to be proportional to the specific surface area of the carbon used in the electrode.

In the case of carbons for supercapacitors, their characterization is carried out routinely with $\mathrm{N}_{2}$ at $77 \mathrm{~K}$ and the most popular approach to evaluate the specific surface rests on the BET method $\left(\mathrm{S}_{\mathrm{BET}}\right)$. The more recent availability of a variety of DFT based- 
methods in commercial adsorption equipments has boosted their use for the assessment of both the pore size distribution (PSD) and the specific surface area ( $\mathrm{S}_{\mathrm{DFT}}$ ). Quite frequently, the average pore size from DFT is combined with $\mathrm{S}_{\mathrm{BET}}$ although they are based on completely different models and $\mathrm{S}_{\mathrm{DFT}}$ and $\mathrm{S}_{\mathrm{BET}}$ are often different [7-9].

The lack of a clear linear relationship between $\mathrm{C}$ and $\mathrm{S}_{\mathrm{BET}}$ or $\mathrm{S}_{\mathrm{DFT}}$ encouraged studies on the specific role of carbon porosity in the formation of the double layer and a variety of interpretations were proposed. Among others, it has been argued that porous carbons often have a significant proportion of narrow micropores inaccessible to ions of electrolyte and, therefore, the entire surface is not used for charge accumulation $[10,11]$. This hypothesis seems reasonable but it results puzzling that the capacitance tends to level off in microporous materials with pores mostly above 1.2-1.5 nm in width and negligible ultramicroporosity $(<0.7 \mathrm{~nm})$. In this context, the limitation of $\mathrm{C}$ in highly porous carbons was ascribed to a space constriction for charge accommodation inside their very thin pore walls. Carbons, being semiconductors, do not feature high chargecarrier density and the space-charge capacitance would be more limited for those with larger surface area $[12,13]$.

It was also suggested that the capacitance corresponds to separate contributions from the surface of the micropores walls $\left(C_{m i}\right)$ and the external surface $\left(C_{e x t}\right)[14,15]$. The fact that the sets of $C_{m i}$ and $C_{e x t}$ values differ between types of carbons [14-19] reveals that this approach does not provide a general description of carbons in SC.

The finding that the double-layer capacitance of the edge orientation of graphite was one order of magnitude higher than that of the basal layer [20] led to conclude that carbons with similar specific surface area but higher ratio of edge/basal orientations would reach higher capacitance [21-23].

More recently, it was pointed out that pores with sizes matching the ions dimensions result more effective for charge storage, maximizing the capacitance normalized to the surface area (in $\mathrm{F} \mathrm{m}^{-2}$ ) $[8,9,24]$.

Finally, it was reported that the puzzling interfacial capacitance found for certain highly porous carbon electrode materials may be originated by a quantum capacitance component of graphene layers, in addition to surface area [25].

In order to address such outstanding questions here we summarize a comprehensive study on the correlations between surface and electrochemical capacitance of a wide variety of carbons tested as SC electrodes under the same conditions. It is found that the standard textural characterization of carbons may be very 
limited to evaluate their actual porosity involved in charge storage. The protocols must be adapted for eliminating possible inconsistencies between textural parameters and capacitance. In fact, a critical re-examination of current insights and theoretical models will certainly benefit the technological development of supercapacitors with optimal performance.

\section{Experimental}

\subsection{Carbons}

This extensive study is based on a wide variety of carbons of different origins and obtained by diverse procedures. They include activated carbons, graphite, nanotemplated mesoporous carbons, carbide derived-carbons, carbon gels, graphene related-materials (graphite oxides, reduced graphite oxides, graphene oxide, etc.). Details on the main structural, textural, chemical and electrochemical characteristics of most of them have been previously reported [18, 26-49].

\subsection{Characterization of the porous structure}

The porosity features of all samples were determined with the help of the combination of different techniques. In a first step, $\mathrm{N}_{2}$ adsorption at $77 \mathrm{~K}$ (Micromeritics ASAP 2010) was used for routine measurements. The specific surface area was determined by the analysis of the isotherm by the BET equation as well as by diverse DFT models (Micromeritics and Quantachrome software packages). Furthermore, the results were cross-checked by applying Kaneko's comparison plot technique and Dubinin's theory. For certain samples, data from the adsorption of $\mathrm{CH}_{2} \mathrm{Cl}_{2}(293 \mathrm{~K}), \mathrm{C}_{6} \mathrm{H}_{6}(293-298 \mathrm{~K}), \mathrm{CO}_{2}(273 \mathrm{~K}), \mathrm{CCl}_{4}(293-298 \mathrm{~K})$ and 2,5norbornadiene $(273 \mathrm{~K}$ ) isotherms (gravimetric McBaine type apparatus) were also used [3-6]. The characterization of a selection of carbons was complemented with the adsorption of $\mathrm{CO}_{2}$ at $273 \mathrm{~K}$ (Micromeritics TriStar 3000) and the corresponding analysis by NLDFT approach and Dubinin-Radushkevich equation. For a better assessment, the surface area was also evaluated by immersion calorimetry into $0.4 \mathrm{M}$ aqueous solution of phenol $[5,6]$. 
Gas adsorption (DFT models) and immersion calorimetry (293 K) into liquids with different critical dimensions provided the pore size distributions $[5,6,38,47]$.

\subsection{Determination of the electrochemical capacitance}

The electrochemical capacitance of carbons was assessed in a sandwich-type capacitor, set up with two carbon pellets $(8-10 \mathrm{mg}, 8 \mathrm{~mm}$ diameter, $100-300 \mu \mathrm{m}$ thickness), separated by a glassy fibrous paper (300 $\mathrm{mm}$ thick) and placed in a Swagelock cell. The electrodes were obtained by pressing a mixture of the carbon (75 $w t \%)$, PVDF (20 wt\%) as binder and carbon black (Super P, $5 \mathrm{wt} \%$ ). Following another procedure, a mixture of $90 \mathrm{wt} \%$ of carbon, $5 \mathrm{wt} \%$ of PTFE and $5 \mathrm{wt} \%$ of Super-P was rolled and punched into pellets. The electrodes were dried overnight in an oven at 100 ${ }^{\circ} \mathrm{C}$ prior to be tested.

The capacitance was determined by galvanostatic charge- discharge cycles (Autolab-Ecochimie PGSTAT 30) at a constant current density of $1 \mathrm{~mA} \mathrm{~cm}^{-2}$ from 0 to $0.8 \mathrm{~V}$ for $2 \mathrm{M}$ aqueous $\mathrm{H}_{2} \mathrm{SO}_{4}$ and between 0 and $2 \mathrm{~V}$ for the organic electrolyte $1 \mathrm{M}$ $\left(\mathrm{C}_{2} \mathrm{H}_{5}\right)_{4} \mathrm{NBF}_{4}$ in acetonitrile $\left(\mathrm{Et}_{4} \mathrm{NBF}_{4} / \mathrm{AN}\right)$. The results were further confirmed by cyclic voltammetry at $1 \mathrm{mV} \mathrm{s}^{-1}$. The values of the gravimetric capacitance $\left(\mathrm{F} \mathrm{g} \mathrm{g}^{-1}\right)$ are relative to the mass of the carbon under study in a single electrode.

\section{Results and Discussion}

\subsection{Specific surface area}

Eq. (1) suggests that a large specific surface area (S) of carbons is the most important parameter leading to a high gravimetric capacitance (C). However, as illustrated by Figs. 1a and b, the gravimetric capacitance of a wide variety of carbons in both aqueous $\left(\mathrm{H}_{2} \mathrm{SO}_{4}\right)$ and organic $\left(\mathrm{Et}_{4} \mathrm{NBF}_{4} / \mathrm{AN}\right)$ electrolytes does not increase linearly with the specific surface area estimated by the standard BET method.

BET equation is the most widely used approach for determining the specific surface area of supercapacitors carbons but its limitations for microporous materials should be taken into account. This equation was developed to explain the adsorption of multilayers on open surfaces and provides reliable values of the specific surface area from the monolayer capacity and the corresponding molecular cross-sectional area of 
the adsorbate. On the contrary, this approach results misleading when applied to microporous carbons since BET-surface reflects the area equivalent to the total volume adsorbed [3-5,50].
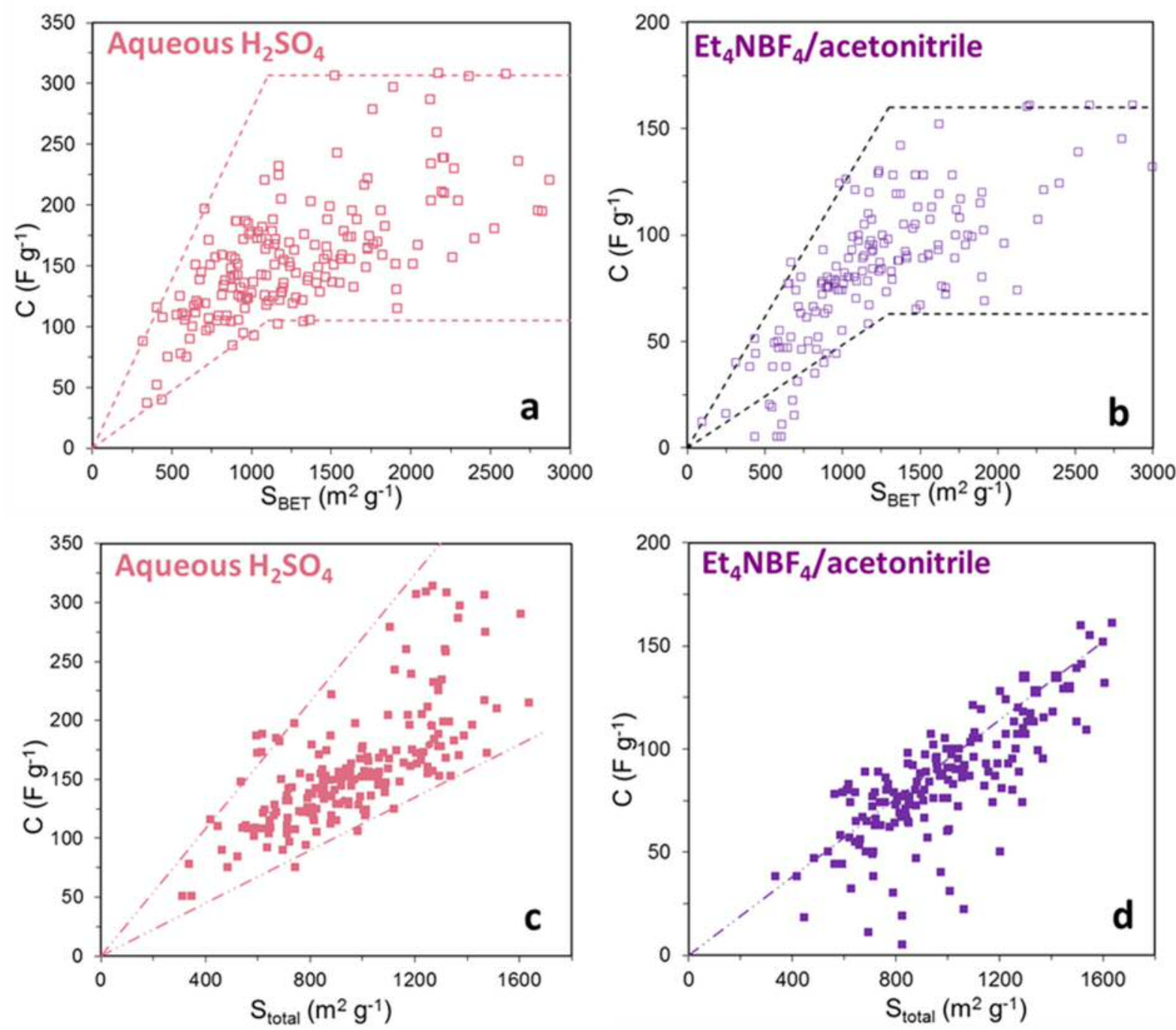

Figure 1. Variation of the specific capacitance of a large variety of carbons [11, 21-46] in $2 \mathrm{M}$ aqueous $\mathrm{H}_{2} \mathrm{SO}_{4}$ and $1 \mathrm{M} \mathrm{Et} \mathrm{NBF}_{4} /$ acetonitrile with the specific surface area estimated by the BET equation ( $a$ and $b$ ) and the total surface area assessed by a combination of different methods (c and d) [5,6,38].

In spite of the specific weaknesses of each of the methods available for the interpretation of physisorption isotherms $[3,4,50]$, the systematic analysis carried out on a variety of carbons has found little discrepancies between areas derived by other 
methods such as comparison plot $\left(\mathrm{S}_{\text {comp }}\right)$, the Dubinin-Radushkevich equation $\left(\mathrm{S}_{\mathrm{DR}}\right)$ and the adsorption of phenol from aqueous solutions $\left(S_{\text {phenol }}\right)[5,28]$. Some scatter of the specific surface area based on the density functional theory $\left(\mathrm{S}_{\mathrm{DFT}}\right)$ with respect to the other determinations [5] derives from the complex nature of such advanced modeling approach with strict requirements [3,4,50] (see Section 3.2).

Instead of relying on a single method, it is more adequate the simultaneous use of several independent approaches in order to cross-check results and eliminate possible contradictions. It has been previously reported $[5,28]$ that the average value of $\mathrm{S}_{\mathrm{DR}}$, $\mathrm{S}_{\text {comp }}, \mathrm{S}_{\mathrm{DFT}}, \mathrm{S}_{\text {phenol }}$ leads to reasonably accurate evaluation of the specific surface area $\left(\mathrm{S}_{\text {total }}\right)$ of numerous carbons. The limitations of the BET equation for microporous carbons are clearly reflected by the quantitative correlation found between $S_{\text {total }}$ and $\mathrm{S}_{\mathrm{BET}}$

$$
S_{\text {total }}=\frac{S_{B E T}}{1.19 L_{o}}
$$

being $\mathrm{L}_{\mathrm{o}}$ the average micropore width.

Eq. 2 reports that $\mathrm{S}_{\mathrm{BET}}$ underestimates the total surface area of carbons with a high proportion of pores below $0.8 \mathrm{~nm}$ and overestimates it in micropores above $1.1 \mathrm{~nm}$ $[5]$.

Figs. 1c and d reveal a totally different pattern for the dependence of $\mathrm{C}$ and $\mathrm{S}$ than that achieved by the standard BET. An increase of the capacitance with the more reliable $S_{\text {total }}$ is suggested, although, in view of the scatter, it is only indicative for the whole spectrum of porous carbons. The absence of a proportionality in Fig. 1c (the dashed lines correspond to surface-capacitances ranging between 0.1 and $0.3 \mathrm{~F} \mathrm{~m}^{-2}$ ) simply reflects the fact that in classical aqueous electrolytes such as $\mathrm{H}_{2} \mathrm{SO}_{4}$ and $\mathrm{KOH}$, the energy storage mechanism does not correspond exclusively to an electrochemical interaction and certain surface functionalities also participate through Faradaic pseudocapacitive reactions [27,39,51-57]. As an additional effect, surface chemistry may also influence the hydrophobic/hydrophilic character of carbons and, therefore, the electrode-electrolyte interaction.

Studies carried out over last decade have reported a pronounced capacitance enhancement by reversible oxidation/reduction of hydroquinone/quinone O-groups $[51,52,54,56]$ and pseudo-capacitive interactions on negatively charged pyrrolic- and 
pyridinic-N functionalities $[55,56]$. Improved electron transfer through the carbon appears to derive from positive charge on quaternary- $\mathrm{N}$ and pyridinic- $\mathrm{N}$-oxide [56].

Quantitative assessments of activated carbons in $2 \mathrm{M}$ aqueous $\mathrm{H}_{2} \mathrm{SO}_{4}$ indicated that the fraction of the surface oxygen desorbed as CO in TPD experiments contributes by around $50-60 \mathrm{~F} \mathrm{mmol}^{-1}[27,39,57]$. The correction of the experimental capacitances by subtracting the corresponding pseudocapacitance from oxygen functionalities led to $0.105 \mathrm{~F} \mathrm{~m}^{-2}$ which virtually corresponds to the effective contribution from the doublelayer in this electrolyte [39]. It coincides with the lower bound displayed in Fig. 1c found for carbons with low oxygen content, independently of the pore width.

The participation of oxygen functionalities was further confirmed by the good agreement observed between the experimental capacitances in $\mathrm{H}_{2} \mathrm{SO}_{4}$ and those calculated from the enthalpies of immersion of carbons into benzene and water [32]. Whereas the enthalpy of immersion into benzene is related to the porous structure, the enthalpy of immersion into $\mathrm{H}_{2} \mathrm{O}$ also reflects the oxygen content of the surface.

The possibility to enhance the energy density of aqueous supercapacitors by pseudocapacitance has stimulated the development of carbon materials with a tailored surface. It has been claimed that outstanding capacitance can be achieved by functionalized carbons with extremely low specific surface areas determined by $\mathrm{N}_{2}$ adsorption at $77 \mathrm{~K}$. Materials derived from biomass wastes [58-60], melamine [61-65], polyaniline [66-71], polypyrrol [72] are able to reach surface-capacitance values ranging from 0.8 to $33 \mathrm{~F} \mathrm{~m}^{-2}$ which are largely beyond the upper-limit of around 0.25 $0.30 \mathrm{~F} \mathrm{~m}^{-2}$ found for typical porous carbons [27,29-31,33-36,39,73]. Such an enhancement is usually attributed to a huge pseudocapacitance afforded by certain surface groups acting as extraordinary redox active sites.

Recent studies by $\mathrm{Wu}$ et al. $[74,75]$ challenged this interpretation by illustrating that the pseudocapacitance of functionalized carbons may be largely overestimated due to inadequate characterization of the porous structure. As previously reported [76], low $\mathrm{N}_{2}$ adsorption capacity of carbons is not always indicative of the absence of pores. $\mathrm{N}_{2}$ at $77 \mathrm{~K}$ is not accurate to assess very narrow porosity, its adsorption being too slow to reach the equilibrium under standard operation times. Such a limitation is usually sorted out by using $\mathrm{CO}_{2}$ at $273 \mathrm{~K}$. Although both molecules display similar dimensions, the higher adsorption temperature allows avoiding diffusional problems and $\mathrm{CO}_{2}$ adsorption results more convenient to evaluate ultramicroporosity [76-79]. 
Textural characterization by $\mathrm{CO}_{2}$ adsorption at $273 \mathrm{~K}$ revealed that the specific surface area of a seaweed-derived carbon was as high as $410 \mathrm{~m}^{2} \mathrm{~g}^{-1}$ instead of $<2 \mathrm{~m}^{2} \mathrm{~g}^{-1}$ probed by $\mathrm{N}_{2}$ at $77 \mathrm{~K}$ [74]. Consequently, the surface capacitance drops from an extraordinary $\mathrm{C} / \mathrm{S}_{\mathrm{N} 2}=58.45 \mathrm{~F} \mathrm{~m}^{-2}$ to a value of $\mathrm{C} / \mathrm{S}_{\mathrm{CO} 2}=0.285 \mathrm{~F} \mathrm{~m}^{-2}$ within the standard ranges reported for functionalized carbons. Further assessments on a variety $\mathrm{N}$-doped carbons [75] confirmed that pores below $0.7 \mathrm{~nm}$ participate actively in the formation of the double-layer in aqueous electrolyte and the initial values of $0.31-2.52 \mathrm{~F} \mathrm{~m}^{-2}$ based on $\mathrm{S}_{\mathrm{N} 2}\left(22-312 \mathrm{~m}^{2} \mathrm{~g}^{-1}\right)$ actually range between 0.16 and $0.28 \mathrm{~F} \mathrm{~m}^{-2}$ when one uses the more reliable $383-587 \mathrm{~m}^{2} \mathrm{~g}^{-1}$ of $\mathrm{S}_{\mathrm{CO} 2}$.

In summary, $\mathrm{N}_{2}$ adsorption at $77 \mathrm{~K}$ provides reliable information on the surface available for charge storage in the case of typical porous carbons but it is not sufficiently accurate to probe materials with a high proportion of ultramicropores. $\mathrm{CO}_{2}$ adsorption at $273 \mathrm{~K}$ has to be implemented for a better estimate of the effective doublelayer in aqueous electrolyte.

\subsection{Surface area accessible to electrolyte ions}

Whereas the total surface area of most porous carbons is virtually accessible to the ions of the aqueous electrolytes, the direct correlation between $\mathrm{C}$ and $\mathrm{S}_{\text {total }}$ clearly fails for a large number of materials in the organic electrolyte $\mathrm{Et}_{4} \mathrm{NBF}_{4} / \mathrm{AN}$ (Fig. 1d).

It should be emphasized that the specific surface areas determined by physical adsorption of standard molecules $\left(\mathrm{N}_{2}, \mathrm{Ar}, \mathrm{CO}_{2}\right)$ involve micropores of widths as low as 0.3-0.4 $\mathrm{nm}$, which are not accessible to larger ions of organic electrolytes [8] and ionic liquids [80]. It follows that predictions based on the classical probes no longer apply and the technique must be adapted in order to provide an accurate assessment of the surface area available to larger ions.

Advanced analyses of the isotherms based on Density Functional Theory (DFT) $[4,81,82]$ have been proposed to provide areas taking into account the ions dimensions [83-85]. With the help of the software of commercial adsorption equipments, the pore size distribution of nanoporous carbons is assessed and, subsequently, the surface area involved in charge storage is calculated by subtracting that in pores smaller than the ions size.

The uncertainties in the characterization of nanoporous carbons using the complex DFT-approaches have been pointed out in the literature $[4,6,50,56,61,86]$. 
Among others, they may lead to very erroneous results for both the total surface area and the pore size distributions if the selected kernel depending on the pores geometry is not consistent with the nanoporous system of the carbons under study.

Very importantly, since DFT-methods are based on a theoretical reference for a given adsorbent/adsorptive system, they must be applied on equilibrium data. Fig. 2 reveals that the results are extremely sensitive to the isotherm accuracy. It contains the combined analysis of $\mathrm{CO}_{2}(\mathrm{NLDFT})$ and $\mathrm{N}_{2}$ (QSDFT) adsorption for a microporous carbide derived-carbon and illustrates how relevant are the equilibrium conditions imposed on the system for taking data.
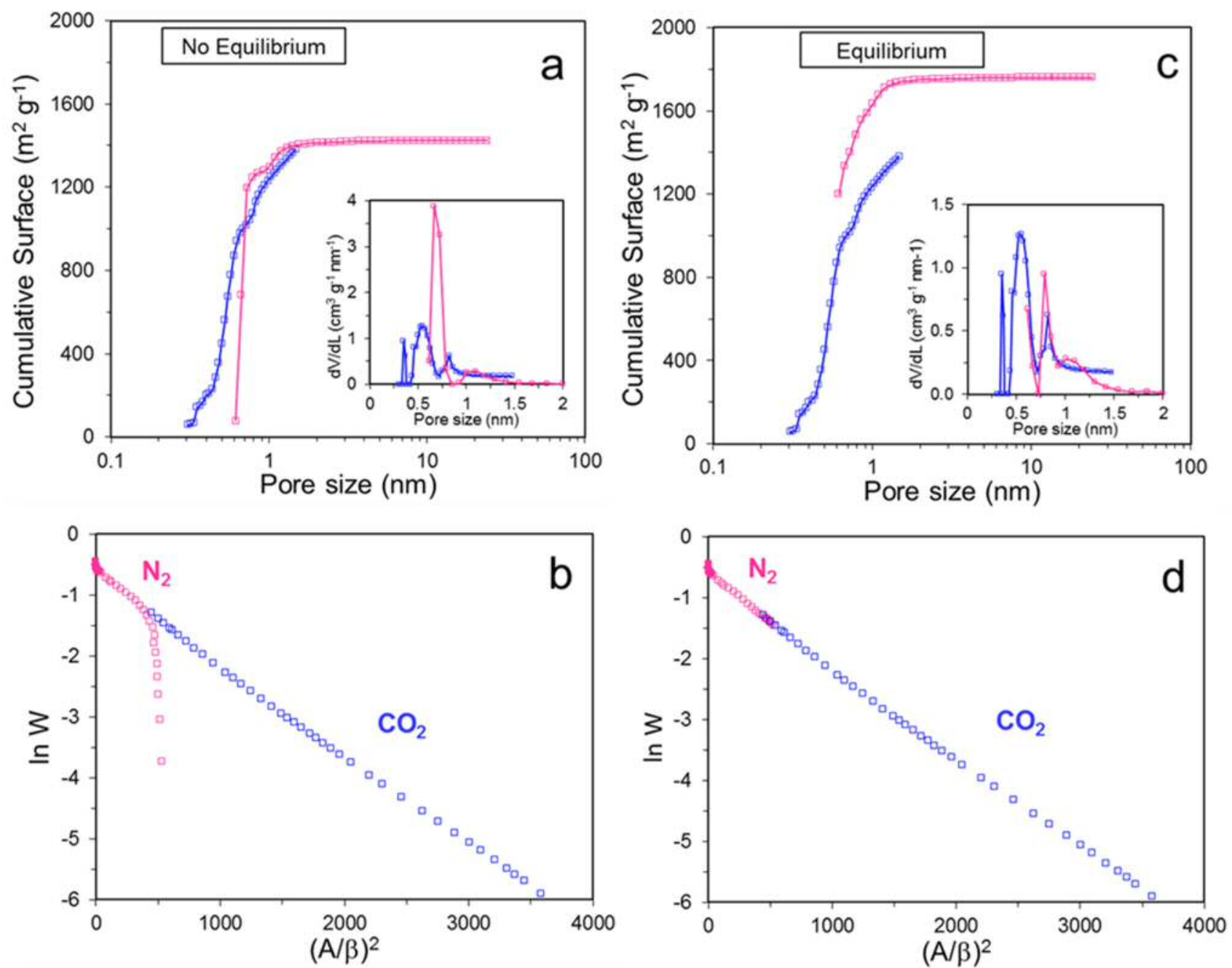

Figure 2. Impact of the time imposed for taking $\mathrm{N}_{2}$ physisorption data on the resulting cumulative surface area ( $\mathrm{a}$ and $\mathrm{c}$ ) and pore size distribution (inset) of a microporous carbide derived carbon. For shake of clarity, the respective D-R plots combining $\mathrm{CO}_{2}$ and $\mathrm{N}_{2}$ adsorption ( $\mathrm{b}$ and $\mathrm{d}$ ) are also shown. 
Whereas the total surface area estimated from the $\mathrm{N}_{2}$ isotherm obtained under standard experimental conditions (i.e. equilibrium interval $=40 \mathrm{~s}$, absolute pressure tolerance $=5$ $\mathrm{mmHg}$ and relative pressure tolerance $=5 \%$ ) is $1425 \mathrm{~m}^{2} \mathrm{~g}^{-1}$, the surface in pores above $0.7 \mathrm{~nm}$ and, therefore, available for the cation $\mathrm{Et}_{4} \mathrm{~N}^{+}(0.68 \mathrm{~nm})$ accounts for $379 \mathrm{~m}^{2} \mathrm{~g}^{-1}$ (Fig. 2a). The clear downward deviation of the low-pressure points observed in the corresponding Dubinin-Radushkevich representation of the isotherm (Fig. 2b) reveals that the $\mathrm{N}_{2}$ adsorption equilibrium was not achieved and, consequently, the QSDFTresults are in error.

Much longer data acquisition time (details in Supplementary Material) allowed to reach comparable $\mathrm{N}_{2}$ and $\mathrm{CO}_{2}$ adsorption at similar relative pressures (Fig. $2 \mathrm{~d}$ ). The better assessment of $\mathrm{N}_{2}$ isotherm reports a total area of $1761 \mathrm{~m}^{2} \mathrm{~g}^{-1}$ whereas the surface available for $\mathrm{Et}_{4} \mathrm{~N}^{+}$is around $759 \mathrm{~m}^{2} \mathrm{~g}^{-1}$, twice than that obtained previously from the routine $\mathrm{N}_{2}$ test.

The need for severe equilibrium inputs to get reliable results from DFT approaches is also shown in Fig. S1 for the activated carbons HK650-8 and PAU-I-950 with average pore widths of 0.66 and $0.75 \mathrm{~nm}$, respectively. On the contrary, with the exception at very low $\mathrm{p} / \mathrm{p}_{\mathrm{o}}$, standard conditions appear to be suitable for the characterization of carbon DCG-5 with a wider porosity centered around $1.15 \mathrm{~nm}$. It is observed that a poor equilibrium also leads to misleading pore size distributions.

In addition to the pore size distribution, unexpected reductions in capacitances are also caused by the so-called "bottle-neck pores". The presence of constrictions at the entrance of the pores, which hinder the access of ions compatible with the pore size, cannot be detected by the classical gas adsorption of small molecules [79,87].

Due to all above limitations, the accurate determination of the surface available for large ions by exclusively adsorption of the standard molecules $\left(\mathrm{N}_{2}, \mathrm{Ar}, \mathrm{CO}_{2}\right)$ results very challenging, especially for carbons with a high proportion of narrow pores. In this context, immersion calorimetry results a powerful tool as the enthalpies of immersion of the carbon into liquids with different molecular dimensions $(0.33-1.5 \mathrm{~nm})$ reveal the volume accessible to the diverse probes. By this complementary technique, one obtains the "effective pore-size distribution" (and implicitly the effective surface areas), as opposed to the adsorption which provides the "absolute PSD" [87]. Recent results based on the combination of $\mathrm{N}_{2}$-physisorption and immersion calorimetry into $\mathrm{CH}_{2} \mathrm{Cl}_{2}(0.33$ $\mathrm{nm}), \mathrm{C}_{6} \mathrm{H}_{6}(0.41 \mathrm{~nm})$ and $\mathrm{CCl}_{4}(0.63 \mathrm{~nm})$ reported that the surface accessible to $\mathrm{Et}_{4} \mathrm{~N}^{+}$ 
was reduced by $20-27 \%$ with respect to the total surface area of carbon monoliths electrodes [47].

So far, the most selective physisorption based-approach to assess the surface involved in charges storage is the use of molecules suiting the critical dimension of ions. With the help of carbon tetrachloride $(0.63 \mathrm{~nm})$ and norbornadiene $(0.65 \mathrm{~nm})$ as convenient probes $[6,32,38]$ for the reliable assessment of the surface area accessible to the cation $\mathrm{Et}_{4} \mathrm{~N}^{+}$, Figure $3 \mathrm{a}$ clearly illustrates that the total surface of a variety of activated carbons is not perceptible for the organic electrolyte. This is particularly remarkable for carbon HK-650-8 with an average micropore size of $0.66 \mathrm{~nm}$, in which $\mathrm{Et}_{4} \mathrm{~N}^{+}$is excluded from $63 \%$ of its surface area. Although not as relevant, the accessibility of the microporous structure is also reduced in the other materials (between $13 \%$ and 27\%). As a limiting case, carbon F02 without pores below $0.7 \mathrm{~nm}$ or constrictions at the pores entrance displays a fully accessible porosity and the total surface area also represents the actual area involved in $\mathrm{Et}_{4} \mathrm{~N}^{+}$adsorption.
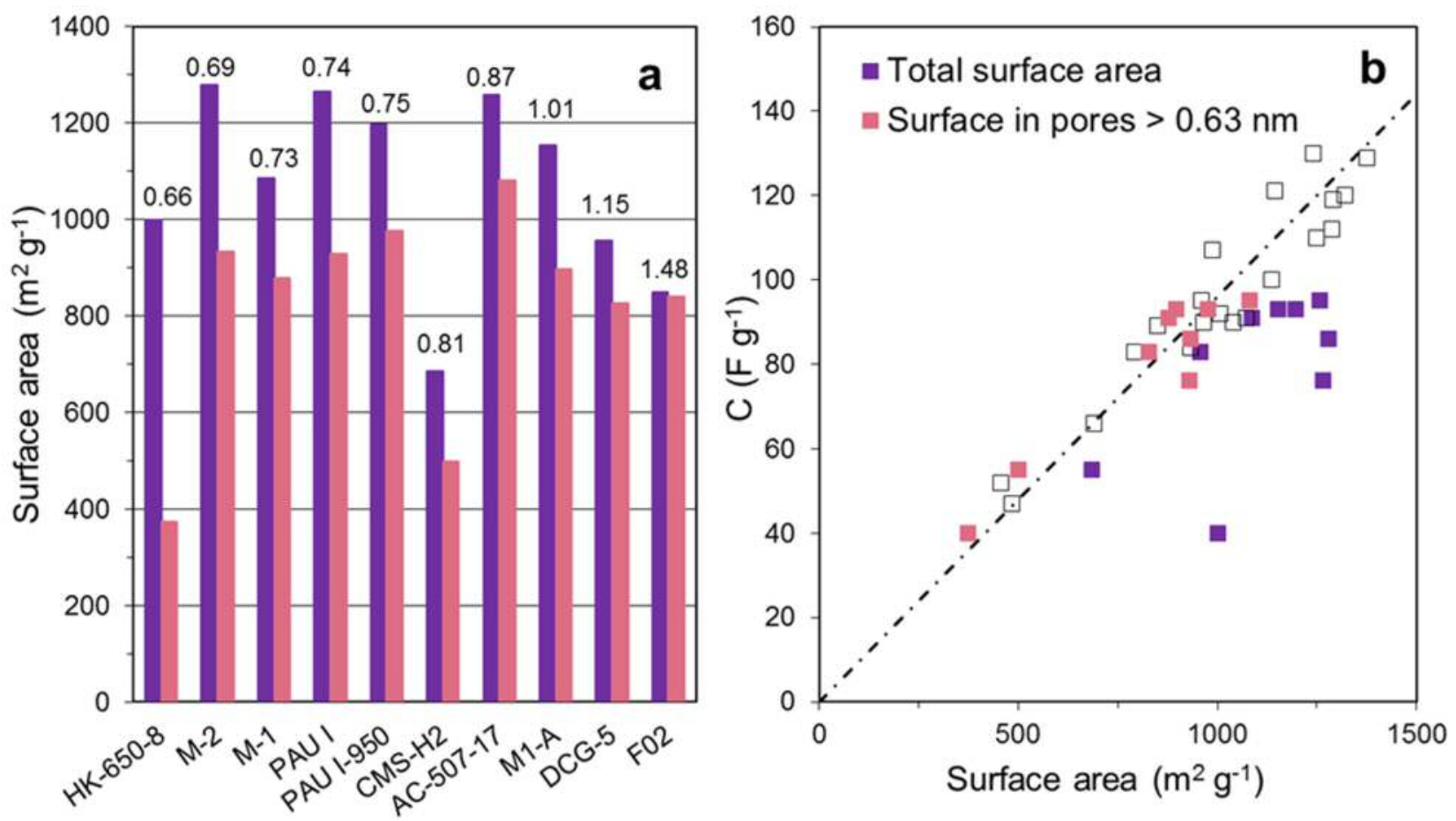

Figure 3. Total surface area ( $\square$ ) and surface in pores larger than $0.63 \mathrm{~nm}(\square)$ for activated carbons with different average micropore size (a) and their correlation with the specific capacitance in the organic $\mathrm{Et}_{4} \mathrm{NBF}_{4} /$ acetonitrile electrolyte (b). For comparison, data for carbons with wide porosity are also included ( $\square)$. The line corresponds to a surface-capacitance of $0.094 \mathrm{~F} \mathrm{~m}^{-2}[38,47]$ 
The determination of the effective surface involved in ions storage leads to an excellent linear correlation between $\mathrm{C}$ in $\mathrm{Et}_{4} \mathrm{NBF}_{4} / \mathrm{AN}$ and $\mathrm{S}$ for different materials with average pore sizes between 0.66 and $15 \mathrm{~nm}$ (Fig. 3b). The deviation from the general pattern observed for carbons with narrow porosity (those of Fig. 3a) disappears when one uses the surface in pores above $0.63 \mathrm{~nm}$. Such a linear relationship indicates that the performance of carbons in this organic electrolyte corresponds essentially to a doublelayer mechanism (as opposed to the behavior in aqueous media) with a virtually constant contribution from the surface of around $0.094 \mathrm{~F} \mathrm{~m}^{-2}$ (dotted line in Fig. 3b) $[38,47]$.

The latter is in contradiction with the increase in surface capacitance claimed for pores smaller than $1 \mathrm{~nm}$ by Gogotsi et al. In a first study [8], such an enhancement was observed for $\mathrm{C} / \mathrm{S}_{\mathrm{BET}}$ but in view of the low reliability of $\mathrm{S}_{\mathrm{BET}}$ to evaluate the surface in microporous carbons $[5,6,38,47,50]$, the issue was recently revisited by using an approach based on the DFT-pore size distributions [84,85]. It consisted in the evaluation of the total surface area by adding the $\mathrm{CO}_{2}$-NLDFT-PSD up to a pore size of $0.9 \mathrm{~nm}$ to the $\mathrm{N}_{2}$-QSDFT-PSD for pores wider than $0.9 \mathrm{~nm}$. In those cases in which the $\mathrm{S}-\mathrm{CO}_{2}$ is higher than $\mathrm{S}-\mathrm{N}_{2}$, the offset is added to the PSD data obtained from $\mathrm{N}_{2}$ isotherm. The surface involved in energy storage is evaluated by taking the surface in pores above the $\mathrm{Et}_{4} \mathrm{~N}^{+}$size.

Figures 2 and S1 suggest that this approximation results too simplistic for ultramicroporous carbons. Firstly, it is not feasible to theoretically determine the appropriate point of intersection of $\mathrm{CO}_{2}$ - and $\mathrm{N}_{2}$-PSD and $0.9 \mathrm{~nm}$ was just qualitatively selected. Secondly, the intersection of both PSDs most likely reflects a poor equilibrium of $\mathrm{N}_{2}$ isotherms of carbons with such a narrow porosity.

Table 1 compares the surface obtained for four activated carbons by using the above DFT-PSDs approach $\left(\mathrm{S}_{>0.63 \mathrm{DFT}}\right)$ and that determined directly with $\mathrm{CCl}_{4}\left(\mathrm{~S}_{\mathrm{CCl} 4}\right)$. It is observed that DFT-PSDs provides much lower surfaces than those assessed with a molecular probe matching the cation size, with the corresponding impact on the surfacecapacitance $\mathrm{C} / \mathrm{S}$. 
Table 1. Porosity features and capacitance in $\mathrm{Et}_{4} \mathrm{NBF}_{4} / \mathrm{AN}$ of various activated carbons

\begin{tabular}{|c|c|c|c|c|c|c|}
\hline \multirow[b]{2}{*}{ Carbon } & \multirow{2}{*}{$\begin{array}{c}\text { Average } \\
\text { pore size } \\
(\mathrm{nm})\end{array}$} & \multicolumn{2}{|c|}{ Surface in pores $>0.63 \mathrm{~nm}$} & \multirow{2}{*}{$\begin{array}{c}\mathrm{C} \\
\left(\mathrm{F} \mathrm{g}^{-1}\right)\end{array}$} & \multicolumn{2}{|c|}{ Surface-capacitance } \\
\hline & & $\begin{array}{c}\mathrm{S}_{\mathrm{CCl} 14} \\
\left(\mathrm{~m}^{2} \mathrm{~g}^{-1}\right)\end{array}$ & $\begin{array}{c}\mathrm{S}_{\mathrm{DFT}} \\
\left(\mathrm{m}^{2} \mathrm{~g}^{-1}\right)\end{array}$ & & $\begin{array}{l}\mathrm{C} / \mathrm{S}_{\mathrm{CCl}} \\
\left(\mathrm{F} \mathrm{m}^{-2}\right)\end{array}$ & $\begin{array}{l}\mathrm{C} / \mathrm{S}_{\mathrm{DFT}} \\
\left(\mathrm{F} \mathrm{m}^{-2}\right)\end{array}$ \\
\hline HK650-8 & 0.66 & 374 & 133 & 40 & 0.107 & 0.300 \\
\hline M-1 & 0.68 & 878 & 264 & 91 & 0.104 & 0.345 \\
\hline PAU I-950 & 0.75 & 977 & 272 & 93 & 0.095 & 0.342 \\
\hline DCG-5 & 1.15 & 827 & 501 & 83 & 0.100 & 0.166 \\
\hline
\end{tabular}

As summarized in Table $1, \mathrm{C} / \mathrm{S}_{>0.63 \mathrm{DFT}}$ achieves $0.30-0.35 \mathrm{~F} \mathrm{~m}^{-2}$ for the ultramicroporous carbons with average pore size of $0.66-0.75 \mathrm{~nm}$ whereas the value is notably reduced to $0.166 \mathrm{~F} \mathrm{~m}^{-2}$ in carbon DCG-5 with a porosity around $1.02 \mathrm{~nm}$. Such noticeable enhancement is not found for the more reliable $\mathrm{C} / \mathrm{S}_{\mathrm{CCl} 4}$, which displays a constant value at around $0.101 \mathrm{~F} \mathrm{~m}^{-2}$, independently of the pores size of carbons. This fits into $0.094 \pm 0.011 \mathrm{~F} \mathrm{~m}^{-2}$ obtained by Stoeckli et al. for diverse porous carbons and recently confirmed by binder-free electrodes made of carbon monoliths with a very narrow micropore size distribution [47]. The latter study refuted the possibility that the presence of binder or wide pore size distributions may hide the variation of the surfacecapacitance with the pore size [88]. The constant pattern for surface-capacitance of carbons obtained experimentally from the effective surface area accessible to the ions agrees with modeling studies [39,41,42,89-92] and would be consistent with a decrease in the relative permittivity $\varepsilon_{\mathrm{r}}$ in narrow micropores [6,93]. Quantitative estimations of the latter by systematic analyses would provide its incidence on the different electrolytes.

The finding of a contribution from the carbon surface of around $0.1 \mathrm{~F} \mathrm{~m}^{-2}$ in both aqueous $\mathrm{H}_{2} \mathrm{SO}_{4}$ and organic $\mathrm{Et}_{4} \mathrm{NBF}_{4} / \mathrm{AN}$ electrolytes has great importance in the field of carbon supercapacitors as it suggests the existence of limits for their energy storage capacity. Thus, the upper-bound for capacitance expressed in $\mathrm{F} \mathrm{g}^{-1}$ would be determined by the specific surface area that can be developed in carbons. Although tremendous progress has been made by engineering appropriate porous structures, an overall assessment based on our own results and data quoted in the literature (the actual surface of microporous carbons was calculated by the correction of the BET-surface by using Eq. 2) suggests that a realistic maximum for the total surface area of carbons is currently around $1700-1800 \mathrm{~m}^{2} \mathrm{~g}^{-1}$ [7,14,28,30,31,33-36,43,71,93-101]. 
The preparation of materials with a much larger surface and hence higher energy storage density is one of the greatest challenges faced by supercapacitors. In this context, graphene with an extremely high surface area of $2630 \mathrm{~m}^{2} \mathrm{~g}^{-1}$, fully accessible to the electrolytes ions, and an outstanding electrical conductivity has emerged as the best candidate for SC electrodes.

\subsection{Extremely low surface area of certain graphene related-materials}

Undoubtedly, graphene has great potential for supercapacitors but its actual application still presents many weaknesses [102-105]. Whereas the synthesis of singlelayer graphene is extremely costly to compete with activated carbons, industrial production provides a wide variety of multilayer-graphenes with chemical and structural imperfectness, which do not reach the expected outstanding performance [103,105-109].

The testing of a variety of graphene materials such as chemically- [110] and thermally-reduced graphene oxide [111,112], microwave exfoliated graphite oxide [113] and chemically activated graphene [114] has reported extremely different values of surface-capacitance. On the basis of the great influence of the preparation methods upon the structural, chemical, textural and electrical properties of the resulting materials, a number of factors and underlying mechanisms have been suggested as responsibles for their different electrochemical performance. Thus, changes in the interfacial capacitance have been ascribed to electronic density of states or quantum capacitance contributions, dimension and number of layers of the graphene stacks, presence of certain functionalities and/or structural defects, ratio of edge/basal carbon atoms, etc. [25,102-105,115-120]. Indeed, all these features play a role but the quantification of their impact requires the accurate determination of the surface involved in the adsorption of ions when the electrodes are charged.

A limiting case corresponds to the atom-thick walls of an activated microwave expanded graphite oxide which provided only $0.06-0.05 \mathrm{~F} \mathrm{~m}^{-2}$ in aqueous and organic electrolytes [114]. The origin of such low value is likely the unreliable surface of 3100 $\mathrm{m}^{2} \mathrm{~g}^{-1}$ assessed for this supermicroporous material by the BET method (Section 3.1). Under similar testing conditions, a chemically reduced graphene oxide with $705 \mathrm{~m}^{2} \mathrm{~g}^{-1}$ displayed standard values of, respectively, 0.19 and $0.13 \mathrm{~F} \mathrm{~m}^{-2}$ [110]. At the other end, one finds the extraordinary 5.5-7.0 $\mathrm{F} \mathrm{m}^{-2}$ achieved in aqueous, organic and ionic liquid electrolytes by lacey reduced graphene oxide nanoribbons [121]. As reported above, the 
latter would simply reflect the inability of $\mathrm{N}_{2}$ adsorption to evaluate the surface operating in charge storage.

Our recent studies have revealed that the approaches described in Sections 3.1 and 3.2 cannot be applied in a straightforward manner for certain graphene relatedcarbons. As summarized in Table 2, expanded graphite oxide (S43 [45]), highly functionalized carbon nanoflakes (OF1, OF2 [48]) and thermally- and chemically $\left(\mathrm{NaBH}_{4}\right)$-reduced graphene oxides (series S77 and GO-B, respectively) display meaningless $\mathrm{C} / \mathrm{S}_{\mathrm{N} 2}$ of 1.7-204 $\mathrm{F} \mathrm{m}^{-2}$ in $\mathrm{H}_{2} \mathrm{SO}_{4}$. Such extremely high values of interfacial capacitance as those observed for $\mathrm{GO} 2-\mathrm{B}$ and $\mathrm{GO} 3-\mathrm{B}$ result from their negligible $\mathrm{N}_{2}$ adsorption capacity (Fig. 4a) which reports a surface not exceeding $1 \mathrm{~m}^{2} \mathrm{~g}^{-1}$ while its gravimetric capacitance is about $100 \mathrm{~F} \mathrm{~g}^{-1}$. Being more accessible to very narrow cavities, the adsorption of $\mathrm{CO}_{2}$ at $273 \mathrm{~K}$ is much more relevant (Fig. $4 \mathrm{~b}$ ) and provides much higher specific surface areas (Table 2).

Table 2. Difference in the specific surface area of graphene related-materials determined by $\mathrm{N}_{2}$ and $\mathrm{CO}_{2}$ adsorption and its impact on the calculation of the surfacecapacitance in the aqueous and organic electrolytes

\begin{tabular}{|c|c|c|c|c|c|c|c|c|}
\hline \multirow{2}{*}{$\begin{array}{l}\text { Graphene } \\
\text { materials }\end{array}$} & \multicolumn{2}{|c|}{$\begin{array}{c}\text { Specific surface } \\
\text { area }\end{array}$} & \multicolumn{3}{|c|}{$2 \mathrm{M} \mathrm{H}_{2} \mathrm{SO}_{4}$} & \multicolumn{3}{|c|}{$1 \mathrm{M} \mathrm{Et}_{4} \mathrm{NBF}_{4} / \mathrm{AN}$} \\
\hline & $\begin{array}{c}\mathrm{S}_{\mathrm{N} 2} \\
\left(\mathrm{~m}^{2} \mathrm{~g}^{-1}\right)\end{array}$ & $\begin{array}{c}\mathrm{S}_{\mathrm{CO} 2} \\
\left(\mathrm{~m}^{2} \mathrm{~g}^{-1}\right)\end{array}$ & $\begin{array}{c}\mathrm{C} \\
\left(\mathrm{F} \mathrm{g}^{-1}\right)\end{array}$ & $\begin{array}{l}\mathrm{C} / \mathrm{S}_{\mathrm{N} 2} \\
\left(\mathrm{~F} \mathrm{~m}^{-2}\right)\end{array}$ & $\begin{array}{l}\mathrm{C} / \mathrm{S}_{\mathrm{CO} 2} \\
\left(\mathrm{~F} \mathrm{~m}^{-2}\right)\end{array}$ & $\begin{array}{c}\mathrm{C} \\
\left(\mathrm{F} \mathrm{g}^{-1}\right)\end{array}$ & $\begin{array}{l}\mathrm{C} / \mathrm{S}_{\mathrm{N} 2} \\
\left(\mathrm{~F} \mathrm{~m}^{-2}\right)\end{array}$ & $\begin{array}{l}\mathrm{C} / \mathrm{S}_{\mathrm{CO} 2} \\
\left(\mathrm{~F} \mathrm{~m}^{-2}\right)\end{array}$ \\
\hline S43 & 15 & 178 & 159 & 10.6 & 0.89 & 82 & 5.47 & 0.46 \\
\hline OF1 & 4 & 96 & 82 & 20.5 & 0.85 & 67 & 16.75 & 0.70 \\
\hline OF2 & 45 & 12 & 104 & 2.31 & 8.67 & 63 & 1.40 & 5.25 \\
\hline $\mathrm{S} 77-400$ & 44 & 293 & 167 & 3.80 & 0.57 & 72 & 1.64 & 0.25 \\
\hline S77-1000 & 48 & 249 & 82 & 1.71 & 0.33 & 14 & 0.29 & 0.06 \\
\hline GO1-B & 5 & 163 & 120 & 24.0 & 0.74 & - & - & - \\
\hline GO2-B & 1 & 429 & 107 & 107 & 0.25 & 7 & 7.0 & 0.02 \\
\hline GO3-B & 0.5 & 99 & 102 & 204 & 1.10 & 7 & 14.0 & 0.07 \\
\hline GO4-B & 21 & 359 & 77 & 3.67 & 0.21 & - & - & - \\
\hline GO5-B & 11 & 478 & 54 & 4.91 & 0.11 & - & - & - \\
\hline
\end{tabular}



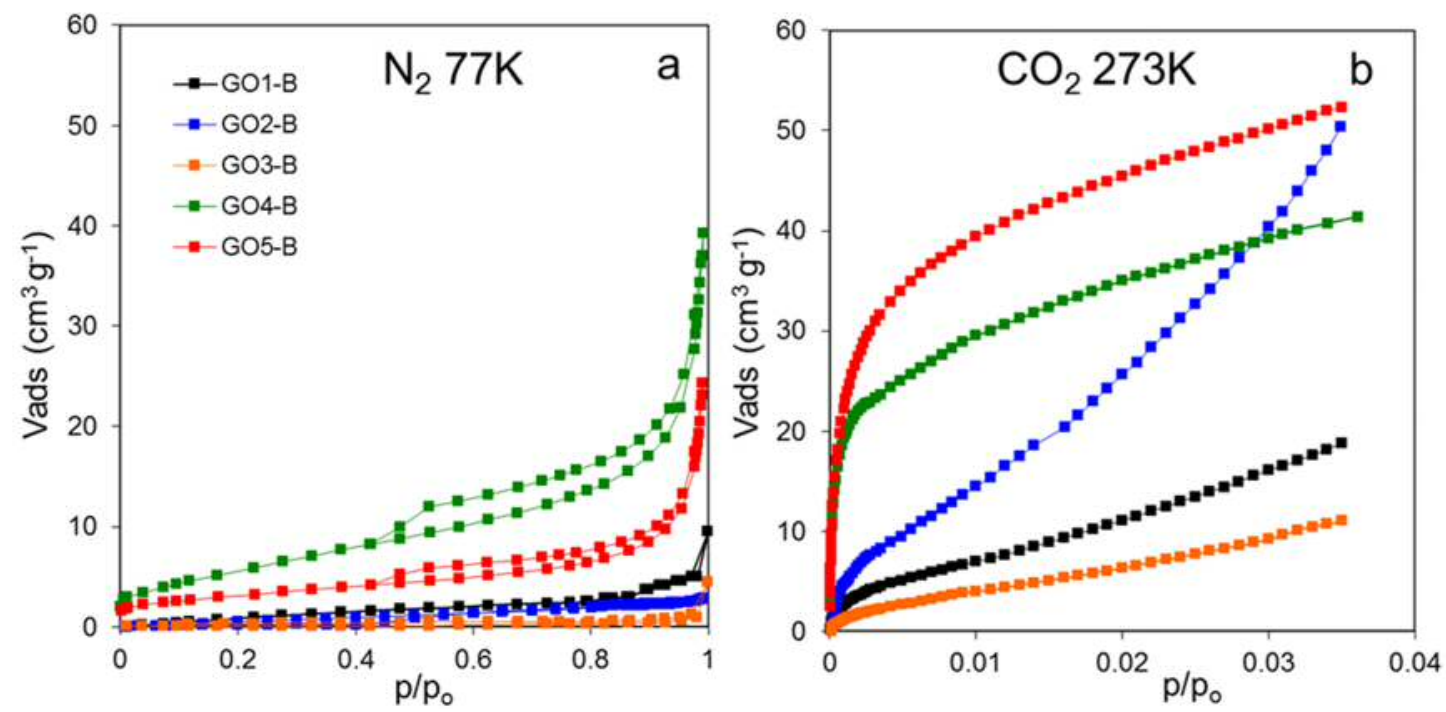

Figure 4. $\mathrm{N}_{2}$ and $\mathrm{CO}_{2}$ isotherms of reduced graphene oxides

However, contrary to its successful use in ultramicroporous carbons (Section 3.1 , it still gives rise to inconsistent values in the range of $0.11-8.67 \mathrm{~F} \mathrm{~m}^{-2}$ for the present graphene type-materials in $\mathrm{H}_{2} \mathrm{SO}_{4}$. The contribution from huge pseudocapacitance due to the incorporation of high amounts of oxygen on graphene sheets cannot be argued as unreasonable $0.3-17 \mathrm{~F} \mathrm{~m}^{-2}\left(\mathrm{C} / \mathrm{S}_{\mathrm{N} 2}\right)$ and $0.02-5.25 \mathrm{~F} \mathrm{~m}^{-2}$ $\left(\mathrm{C} / \mathrm{S}_{\mathrm{CO} 2}\right)$ are also displayed in the organic electrolyte, in which the pseudocapacitance is negligible [29].

Although other factors may be contributing to increase the interfacial capacitance of graphene materials, these unusual values suggest that the specific surface measured by standard gas adsorption may not be a relevant parameter for the present cases. It should be noted that the preparation of the materials quoted in Table 2 involved the expansion of graphitic structures by intercalation of oxygen-containing groups between graphene layers. It is very likely that electrochemical cycling facilitates the access of electrolyte ions to the interlayer space (channels, cavities) by a voltage-driven mechanism [122-125], providing a surface area larger than that estimated by gas physisorption. Therefore, outstanding surface-capacitance of graphene materials is not excluded but it may be affected by the difficulty to estimate accurately the actual surface area involved in energy storage.

No less important, one must be aware that the majority of the results reported in the literature for graphene-based supercapacitors are obtained by using electrodes with 
extremely low weight. This may result in inaccurate calculations of the gravimetric capacitance and, consequently, of the interfacial capacitance.

\subsection{Surface area of carbons when processed in electrodes}

An important issue for the identification of the parameters determining the performance carbon based-SC concerns the integrity of the porous structure of carbons when are processed into electrodes. The effect of pore blocking due to the addition of binder is frequently argued to explain the absence of a proportionality between the specific surface area and the electrochemical capacitance $[85,88]$.

At a glance, the HRSEM image of a commercial electrode consisting of an activated carbon and 10\% PTFE (Fig. 5-inset) does not show a bulk coating of carbon particles by the binder. This agrees with the quite similar values of enthalpy of immersion into benzene obtained for the powdered carbon and the corresponding electrode (175.3 and $153.1 \mathrm{~J} \mathrm{~g}^{-1}$, respectively). Further evaluation of the specific surface area revealed a decrease of only $8 \%$ after electrode processing (Fig. 5).

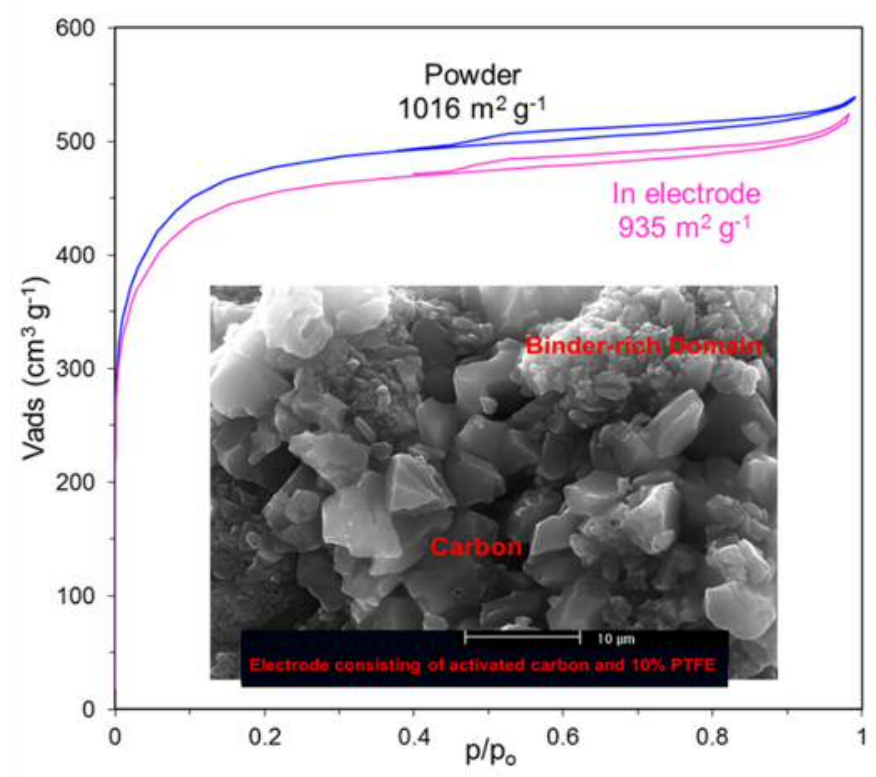

Figure 5. $\mathrm{N}_{2}$ adsorption isotherms of a powdered activated carbon and the corresponding electrode with $10 \%$ of PTFE as binder (inset-SEM image). The data for the electrode are referred to the mass of activated carbon. 
The results of a comprehensive assessment by $\mathrm{N}_{2}$ adsorption of the porosity of various carbon electrodes compiled in Fig. 6 illustrate that the processing with 5\% of PTFE or even with excess of $20 \%$ of PVDF reduces the specific surface area of typical activated carbons by less than $10 \%$. Furthermore, no significant change in PSD (not shown) has been detected. Unlike reported by Abbas et al. [126], Fig. S2 reveals no significant incidence of the binder type on the porosity loss, the differences being within the limits of experimental error of $\mathrm{N}_{2}$ adsorption.

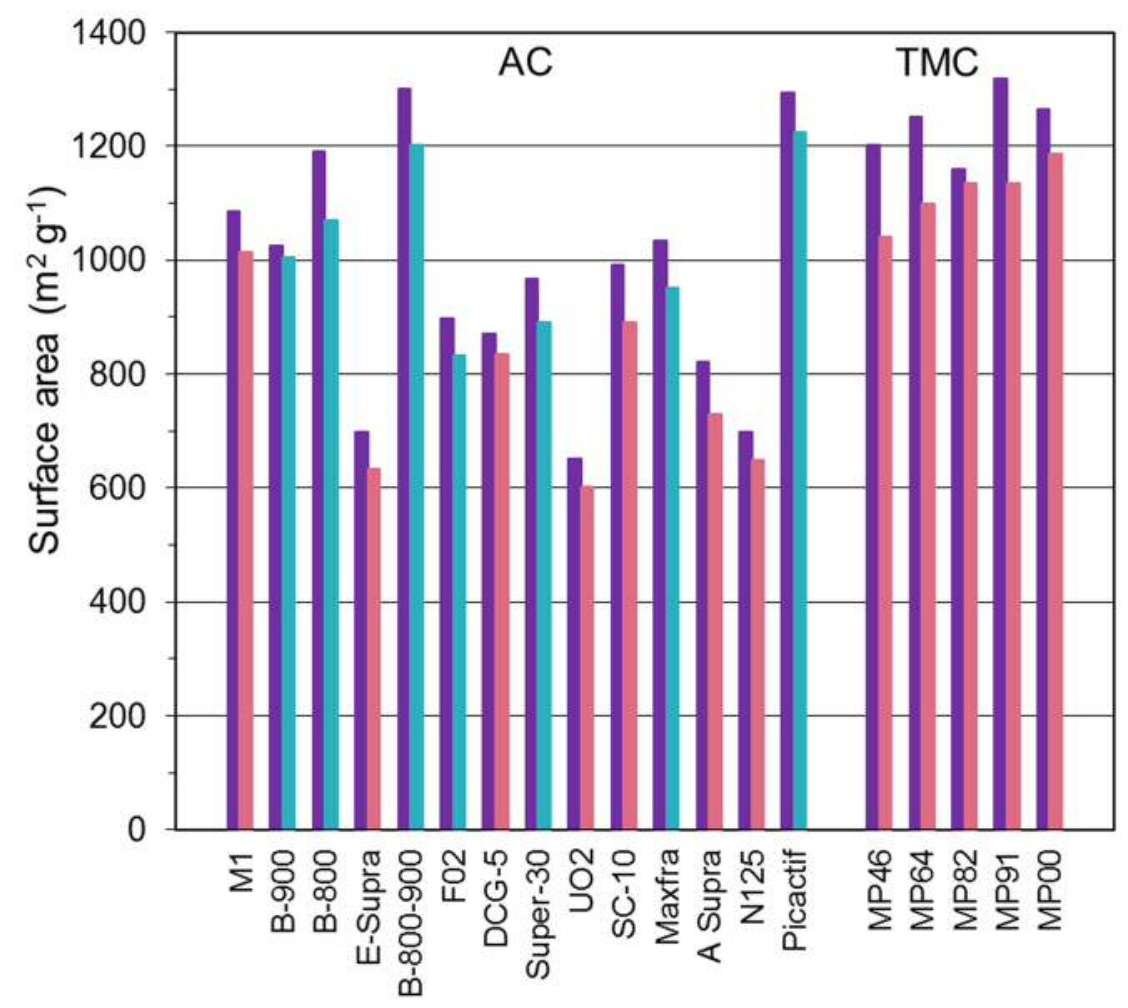

Figure 6. Specific surface area of activated carbons (AC) and templated mesoporous carbons (TMC) in powdered form ( $\square$ ) and in the corresponding electrodes processed with $20 \%$ of PVDF ( $\square$ ) or $5 \%$ of PTFE ( $\square$ ). The values for the electrodes are referred to the mass of porous carbon.

It is important to note that even for the extremely ultramicroporous carbon monolith M1 with narrow pore size distribution around $0.73 \mathrm{~nm}$, the surface area undergoes a reduction of only $7 \%$ when the material is ground and compacted with $20 \%$ PVDF to form a film electrode. In the case of templated mesoporous carbons obtained by carbonization of mixtures of a thermoplastic precursor with magnesium citrate [31], the maximum decrease in surface is limited to $12 \%$. 
With such low differences, the correlation of the surface of the raw carbons (in powder) with electrochemical performance of the film electrodes (Fig. 1 and 3b) does not yield a significant discrepancy. Besides the results previously obtained for binderfree carbon monoliths [47], the present findings reject that the binder hides an increase of $\mathrm{C} / \mathrm{S}$ in ultramicropores $[8,88]$ and support the reliability of constant surfacecapacitance in carbons $[38,39]$.

Indeed, the limited incidence of the binder on the porosity loss observed for the variety of the above materials should not be extrapolated for all carbons and each case requires to be evaluated. Thus, further studies have shown that problems may arise for some advanced carbons. Recently, it has been pointed out the precautions which must be taken for the SC assessment of ordered mesoporous carbons (OMCs) obtained from 3-aminobenzoic acid with SBA-15 as template [49]. As illustrated by Fig. S3, their outstanding structure consisting in chains of particles with bean-like shape is not preserved after the fabrication of electrodes matching the thickness and the carbon loading of commercial devices, and their specific surface area can be reduced by almost half. The detection of such a porosity loss allowed to evidence the remarkable electrochemical activity of the surface complexes, contrary to what suggested when the specific capacitance was related to the surface area of the materials in powdered form [49].

Constraints also detected for graphene-based materials should not be underestimated. Fig. 7a illustrates the drop of surface area (up to 55\%) when graphene materials obtained by wet oxidation of graphite are shaped into electrodes. 

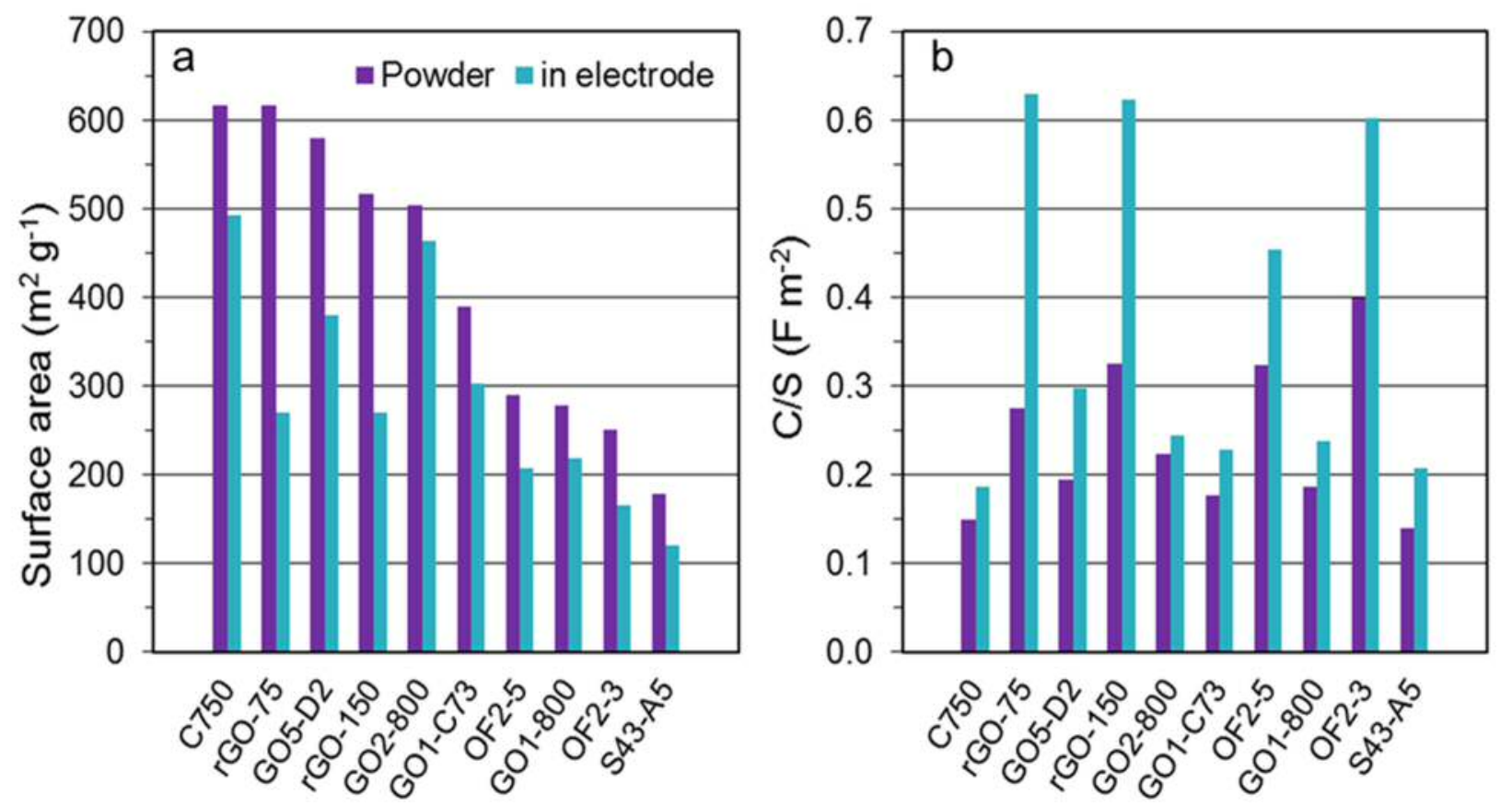

Figure 7. Surface area of a variety of graphene related-materials in powdered form and processed in electrodes (a) and the corresponding capacitance normalized to surface (b).

It appears that the expanded structure experiences some re-stacking whereas the voids between graphene-type flakes GO5-D2 and rGO-75 (Fig. 8) are also significantly reduced by following standard electrode processing.
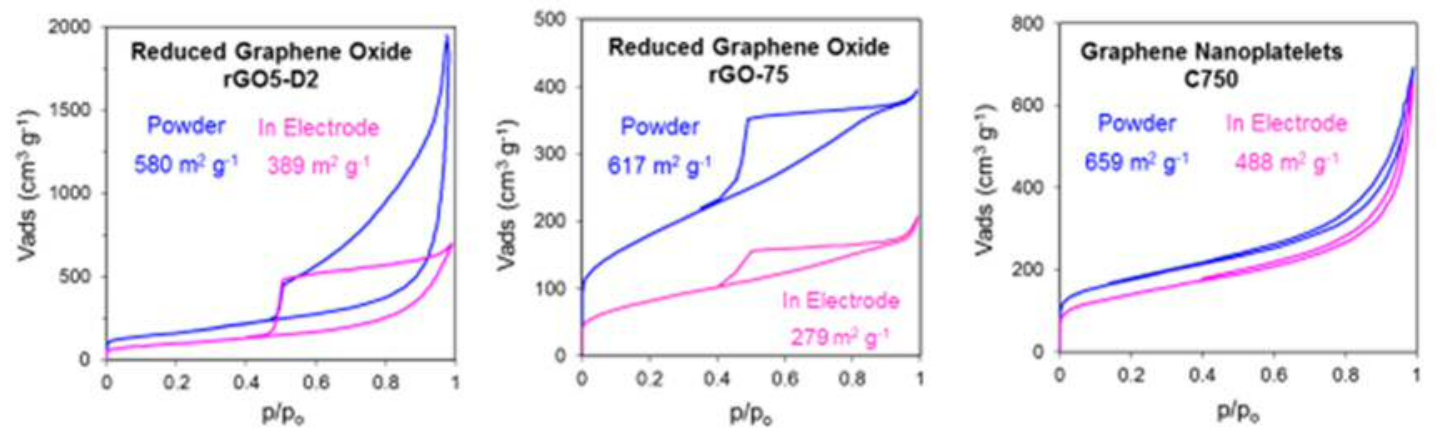

Figure 8. $\mathrm{N}_{2}$ isotherms for diverse graphene-type materials and the corresponding electrodes with 5\% PTFE. For the electrodes, the volume and the surface values are referred to the mass of active material. 
As stressed by Fig. 7b, totally different values for the interface capacitance are obtained depending on the surface taken for calculations. This should be considered in order to get reliable interpretation of the graphene performance in supercapacitors.

The much lower surface loss in the case of processing graphene nanoplatelets C750 derived by mechanical exfoliation of graphite (Fig. 8), suggests that there is no general pattern and the electrode preparation must attend to the specific features of each graphene material. This is another relevant challenge for the application of graphene as active material in supercapacitor electrodes.

\section{Conclusions}

Besides the $\mathrm{S}_{\mathrm{BET}}$ and $\mathrm{S}_{\mathrm{DFT}}$ based on $\mathrm{N}_{2}$ adsorption which are mostly adopted for the characterization of carbons for supercapacitors, other approaches have to be considered.

Whereas the analysis of $\mathrm{N}_{2}$ isotherm by a combination of different methods leads to excellent correlations between the total surface area and the specific capacitance of typical porous carbons in $\mathrm{H}_{2} \mathrm{SO}_{4}$ aqueous electrolyte, $\mathrm{CO}_{2}$ adsorption has to be implemented for a better estimate of the effective double-layer in carbons with a high contribution from ultramicropores.

The aqueous electrolyte virtually uses the entire surface area of porous carbons but the adsorption of larger ions of organic electrolyte $\mathrm{Et}_{4} \mathrm{NBF}_{4} /$ acetonitrile is notably affected by the existence of a pore size distribution and/or constrictions at the entrance of the pores. Therefore, the specific surface area determined by standard gas adsorption (i.e. $\mathrm{N}_{2}$ and $\mathrm{CO}_{2}$ as adsorbates) may not be a relevant parameter and the surface available for charge storage has to be estimated by using molecular probes with similar dimensions to the ions.

The effective surface area accessible to the ions, which may differ considerably from the BET-surface and the more advanced DFT-PSD derived-surface, leads to a virtually constant surface-capacitance for carbons in both $\mathrm{H}_{2} \mathrm{SO}_{4}$ and $\mathrm{Et}_{4} \mathrm{NBF}_{4} /$ acetonitrile of around $0.1 \mathrm{~F} \mathrm{~m}^{-2}$, independently of the pore size. This finding is of great importance for $R \& D$ of carbon supercapacitors as it suggests the existence of limits for their energy storage capacity. In the absence of pseudocapacitive contributions, the upper-bound for capacitance expressed in $\mathrm{F} \mathrm{g}^{-1}$ would be essentially determined by the surface area available to ions that can be generated in carbons. 
The determination of the surface area involved in the formation of the doublelayer in certain graphene-materials is an actual challenge. It appears that electrochemical operation (based on a voltage driven-process) facilitates the access of electrolyte ions to the expanded structure resulted from harsh oxidation of graphitic precursors. Therefore, standard gas adsorption may result useless for some graphene type-materials as it does not always match their electrochemically active area.

Another important concern is the significant textural changes experienced by some advanced carbons when processed in electrodes with features of commercial devices.

Due to the impact of all these issues on the knowledge of the supercapacitor performance, the characterization protocols must be adapted for this specific application of carbons.

\section{Acknowledgements}

Financial support from EU 7FP (Project Electrograph-266391) is gratefully acknowledged. L.S. thanks the support from Programa Estatal de Promoción del Talento y su Empleabilidad en $\mathrm{I}+\mathrm{D}+\mathrm{i}$ and European Social Fund-Youth Employment Initiative.

The authors wish to thank Danubia Nanotech sro. (Slovakia) and Abalonyx AS (Norway) for the gift of graphene materials of series GO-B and S77, respectively.

\section{Appendix A. Supplementary data}

Supplementary data related to this article can be found at 


\section{References}

[1] Tascón JMD. Novel Carbon Adsorbents, Amsterdam: Elsevier; 2012.

[2] Beguin F, Frackowiack E. Carbons for electrochemical energy storage and conversion systems, Boca Raton: CRC Press; 2010.

[3] Rouquerol J, Avnir D, Fairbridge CW, Everett DH, Haynes JM, Pernicone N, Ramsay JDF, Sing KSW, Unger KK, Recommendations for the characterization of porous solids. Pure Appl Chem 1994; 66: 1739-58.

[4] Thommes M, Kaneko K, Neimark AV, Olivier JP, Rodriguez-Reinoso F, Rouquerol J, Sing KSW. Physisorption of gases, with special reference to the evaluation of surface area and pore size distribution. Pure Appl Chem 2015; 87: 1051-69.

[5] Centeno TA, Stoeckli F. The assessment of surface areas in porous carbons by model-independent techniques, the DR equation and DFT. Carbon 2010; 48: 2478-86.

[6] Stoeckli F, Centeno TA. Optimization of the characterization of porous carbons for supercapacitors. J Mater Chem A 2013; 1: 6865-73.

[7] Chmiola J, Yushin G, Dash R, Gogotsi Y. Effect of pore size and surface area of carbide derived carbons on specific capacitance. J Power Sources 2006; 158: 765-72.

[8] Chmiola J, Yushin G, Gogotsi Y, Portet C, Simon P, Taberna PL. Anomalous increase in carbon capacitance at pore sizes less than $1 \mathrm{~nm}$. Science 2006; 313: 1760-3.

[9] Largeot C, Portet C, Chmiola J, Taberna PL, Gogotsi Y, Simon P, Relation between the ion size and pore size for an electric double-layer capacitor. J Am Chem Soc 2008; 130: $2730-1$.

[10] Yan J, Wang Q, Wei T,Fan Z. Recent advances in design and fabrication of electrochemical supercapacitors with high energy densities. Adv Energy Mater 2014; 4: 1300816.

[11] Pandolfo AG, Hollenkamp AF. Carbon properties and their role in supercapacitors. J Power Sources 2006; 157: 11-27.

[12] Barbieri O, Hahn M, Herzog A, Kötz R. Capacitance limits of high surface area activated carbons for double layer capacitors. Carbon 2005; 43: 1303-10.

[13] Lazzari M, Soavi F, Mastragostino M. Mesoporous carbon design for ionic liquidbased, double-layer supercapacitors. Fuel Cells 2010; 10: 840-847.

[14] Qu D, Shi H. Studies of activated carbons used in double-layer capacitors. J Power Sources 1998; 74: 99-107.

[15] Shi H. Activated carbons and double layer capacitance. Electrochim Acta 1996; 41: $1633-9$. 
[16] Wang L, Fujita M, Inagaki M. Relationship between pore surface areas and electric double layer capacitance in non-aqueous electrolytes for air-oxidized carbon spheres. Electrochim Acta 2006; 51: 4096-102.

[17] Gryglewicz G, Machnikowski J, Grabowska E, Lota G, Frackowiak E. Effect of pore size distribution of coal-based activated carbons on double layer capacitance. Electrochim Acta 2005; 50: 1197-206.

[18] Li-Hong W, Toyoda M, Inagaki M. Dependence of electric double layer capacitance of activated carbons on the types of pores and their surface areas. New Carbon Mater 2008; 23: 111-5.

[19] Centeno TA, Stoeckli, F. In: Editor: Gupta V, editor. Recent Advances in Supercapacitors, Kerala; Transworld Research Network; 2006 p. 57-77.

[20] Randin JP, Yeager E. Differential capacitance study on the basal plane of stressannealed pyrolytic graphite. J Electroanal Chem Interfacial Electrochem 1972; 36: 25776.

[21] Randin JP, Yeager E. Differential capacitance study on the edge orientation of pyrolytic graphite and glassy carbon electrodes. J Electroanal Chem Interfacial Electrochem 1975; 58: 313-22.

[22] Qu D. Studies of the activated carbons used in double-layer supercapacitors. J Power Sources 2002; 109: 403-411.

[23] Kim T, Lim S, Kwon K, Hong, S-H, Qiao W, Rhee CK, et al. Electrochemical capacitances of well-defined carbon surfaces. Langmuir 2006; 22: 9086-8.

[24] Raymundo-Piñero E, Kierzek K, Machnikowski J, Beguin F. Relationship between the nanoporous texture of activated carbons and their capacitance properties in different electrolytes. Carbon 2006; 44: 2498-507.

[25] Ji H, Zhao X, Qiao Z, Jung J, Zhu Y, Lu Y, et al. Capacitance of carbon-based electrical double-layer capacitors. Nat Commun 2014; 5: No. 3317.

[26] Centeno TA, Stoeckli F. On the specific double layer capacitance of activated carbons, in relation to their structural and chemical properties. J. Power Sources 2006; 154: 314-20.

[27] Centeno TA, Stoeckli F. The role of textural characteristics and oxygen-containing surface groups in the supercapacitor performances of activated carbons. Electrochim Acta 2006; 52: 560-6

[28] Sevilla M, Alvarez, S, Centeno TA, Fuertes AB, Stoeckli F. Performance of templated mesoporous carbons in supercapacitors. Electrochim Acta 2007; 52: 3207-15. 
[29] Centeno TA, Hahn M, Fernández JA, Kötz R, Stoeckli F. Correlation between capacitances of porous carbons in acidic and aprotic EDLC electrolytes. Electrochem Comm 2007; 9: 1242-6.

[30] Lota G, Centeno TA, Frackowiak E, Stoeckli F. Improvement of the structural and chemical properties of a commercial activated carbon for its application in electrochemical capacitors. Electrochim Acta 2008; 53: 2210-6.

[31] Fernández JA, Morishita T, Toyoda M, Inagaki M, Stoeckli F, Centeno TA. Performance of mesoporous carbons derived from poly (vinyl alcohol) in electrochemical capacitors. J. Power Sources 2008; 175: 675-9.

[32] Centeno TA, Fernández JA, Stoeckli F. Correlation between heats of immersion and limiting capacitances in porous carbons. Carbon 2008; 46: 1025-30.

[33] Fernández JA, Arulepp M, Leis J, Stoeckli F, Centeno TA. EDLC performance of carbide-derived carbons in aprotic and acidic electrolytes. Electrochim Acta 2008; 53: 7111-6.

[34] Olivares-Marín M, Fernández JA, Lázaro MJ, Fernández-González C, MacíasGarcía A, Gómez-Serrano V, Stoeckli F, Centeno TA. Cherry stones as precursor of activated carbons for supercapacitors. Mater Chem Phys 2009; 114: 323-7.

[35] Fernández JA, Tennison S, Kozynchenko O, Rubiera F, Stoeckli F, Centeno TA. Effect of mesoporosity on specific capacitance of carbons. Carbon 2009; 47: 15981604 .

[36] Domingo-García M, Fernández JA, Almazán-Almazán MC, López-Garzón FJ, Stoeckli F, Centeno TA. Poly(ethylene terephthalate)-based carbons as electrode material in supercapacitors. J Power Sources 2010; 195: 3810-3.

[37] Sánchez-González J, Stoeckli F, Centeno TA. The role of the electric conductivity of carbons in the supercapacitor performance. J Electroanal Chem 2011; 657: 176-80

[38] Centeno TA, Sereda O, Stoeckli F. Capacitance in carbon pores of 0.7 to $15 \mathrm{~nm}$ : a regular pattern. Phys Chem Chem Phys 2011; 13: 12403-6 (2011).

[39] Centeno TA, Stoeckli F. Surface-related capacitance of microporous carbons in aqueous and organic electrolytes. Electrochim Acta 2011; 56: 7334-9.

[40] González-García P, Centeno TA, Urones-Garrote E, Ávila-Brande D, Otero-Díaz LC. Porous carbon nanospheres derived from chlorination of bis(ciclopentadienyl)titanium dichloride and their electrochemical capacitor performance. Mater. Chem. Phys 2011; 130: 243-50.

[41] Centeno TA, Stoeckli F. The volumetric capacitance of microporous carbons in 
organic electrolyte. Electrochem Comm 2012; 16: 34-6.

[42] Stoeckli F, Centeno TA. Pore size distribution and capacitance in microporous carbons. Phys Chem Chem Phys 2012; 14: 11589-91.

[43] Dobele G, Dizhbite T, Gil MV, Volpert A, Centeno TA. Production of nanoporous carbons from wood processing wastes and their use in supercapacitors and $\mathrm{CO}_{2}$ capture. Biomass Bioenerg 2012; 46: 145-54.

[44] Pohlmann S, Lobato B, Centeno TA, Balducci A. The influence of pore size and surface area of activated carbons on the performance of ionic liquid based supercapacitors. Phys Chem Chem Phys 2013; 15:17287-94.

[45] Lobato B, Wendelbo R, Barranco V, Centeno TA. Graphite Oxide: An Interesting Candidate for Aqueous Supercapacitors. Electrochim Acta 2014; 149: 245-51.

[46] Lobato B, Vretenar V, Kotrusz P, Hulman M, Centeno TA. Reduced graphite oxide in supercapacitor electrodes. J Colloid Interface Sci 2015; 446: 203-7.

[47] García-Gómez A, Moreno-Fernández G, Lobato B, Centeno TA. Constant capacitance in nanopores of carbon monoliths. Phys Chem Chem Phys 2015; 17:1568790 .

[48] Lobato B, Merino C, Barranco V, Centeno TA. Large-scale conversion of helicalribbon carbon nanofibers to a variety of graphene-related materials. RSC Adv 2016; 6: 57514-20.

[49] Sánchez-Sánchez A, Centeno TA, Suarez-García F, Martínez-Alonso A, Tascón JMD. The importance of electrode characterization to assess the supercapacitor performance of ordered mesoporous carbons. Micropor Mesopor Mat 2016; 235:1-8.

[50] Lozano-Castelló D, Suárez-García F, Cazorla-Amorós D, Linares-Solano, A. Porous texture of carbons. In: Béguin F, Frackowiak E, editors. Carbons for electrochemical energy storage and conversion systems, Boca Raton: CRC Press; 2010, p. 115-62.

[51] Andreas HA, Conway BE, Examination of the double-layer capacitance of a high specific-area C-cloth electrode as titrated from acidic to alkaline $\mathrm{pHs}$. Electrochim Acta 2006; 51: 6510-20.

[52] Okajima K, Ohta K, Sudoh M. Capacitance behaviour of activated carbon fibers with oxygen-plasma treatment. Electrochim Acta 2005; 50: 2227-31.

[53] Bleda-Martínez MJ, Macia-Agulló JA, Lozano-Castelló D, Morallón E, CazorlaAmoros D, Linares-Solano A. Role of surface chemistry on electric double layer capacitance of carbon materials. Carbon 2005; 43: 2677-84. 
[54] Raymundo-Piñero E, Leroux F, Béguin F. A high-performance carbon for supercapacitors obtained by carbonization of a seaweed biopolymer. Adv Mater 2006; 18: $1877-82$.

[55] Seredych M, Hulicova-Jurcakova D, Lu GQ, Bandosz TJ. Surface functional groups of carbons and the effects of their chemical character, density and accessibility to ions on electrochemical performance. Carbon 2008; 46: 1475-88.

[56] Hulicova-Jurcakova D, Seredych M, Lu GQ, Bandosz TJ. Combined effect of nitrogen- and oxygen-containing functional groups of microporous activated carbon on its electrochemical performance in supercapacitors. Adv Funct. Mater 2009; 19: 438-47. [57] Barranco V, Lillo-Rodenas MA, Linares-Solano A, Oya A, Picó F, Ibáñez J, Agullo-Rueda F, Amarilla JM, Rojo JM. Amorphous carbon nanofibers and their activated carbon nanofibers as supercapacitor electrodes. J Phys Chem C 2010; 114: 10302-7.

[58] Li Z, Zhang L, Amirkhiz BS, Tan X, Xu Z, Wang H, Olsen BC, Holt CMB, Mitlin D. Carbonized chicken eggshell membranes with 3D architectures as high-performance electrode materials for supercapacitors. Adv Energy Mater 2012; 2: 431-7.

[59] Senthilkumar ST, Senthilkumar B, Balaji S, Sanjeeviraja C, Selvan RK. Preparation of activated carbon from sorghum pith and its structural and electrochemical properties. Mater Res Bull 2011; 46: 413-9.

[60] Raymundo-Piñero E, Cadek M, Béguin F. Tuning carbon materials for supercapacitors by direct pyrolysis of seaweeds. Adv Funct Mater 2009; 19:1032-9.

[61] Hulicova D, Yamashita J, Soneda Y, Hatori H, Kodama M. Supercapacitors prepared from melamine-based carbon. Chem Mater 2005; 17: 1241-7.

[62] Hulicova-Jurcakova D, Kodama M, Shiraishi S, Hatori H, Zhu ZH, Lu GQ. Nitrogen-enriched nonporous carbon electrodes with extraordinary supercapacitance. Adv Funct Mater 2009; 19: 1800-9.

[63] Kim KS, Park SJ. Synthesis of nitrogen doped microporous carbons prepared by activation-free method and their high electrochemical performance. Electrochim Acta 2011; 56: 10130-6.

[64] Xiang X, Liu E, Xie H, Tian Y, Wu Y, Wu Z, Zhu Y. Highly stable performance of supercapacitors using microporous carbon derived from phenol-melamineformaldehyde resin. J Solid State Electrochem 2012; 16: 2661-6. 
[65] Ma C, Song Y, Shi J, Zhang D, Guo Q, Liu L. Preparation and electrochemical performance of heteroatom-enriched electrospun carbon nanofibers from melamine formaldehyde resin. J Colloid Interface Sci 2013; 395: 217-23.

[66] Yan J, Wei T, Qiao W, Fan Z, Zhang L, Li T, Zhao Q. A high-performance carbon derived from polyaniline for supercapacitors. Electrochem Commun 2010; 12: 1279-82. [67] Yang M, Cheng B, Song H, Chen X Preparation and electrochemical performance of polyaniline-based carbon nanotubes as electrode material for supercapacitor. Electrochim Acta 2010; 55: 7021-7.

[68] Li L, Liu E, Shen H, Yang Y, Huang Z, Xiang X, Tian Y. Charge storage performance of doped carbons prepared from polyaniline for supercapacitors. J Solid State Electrochem 2011; 15: 175-82.

[69] Gavrilov N, Pasti IA, Vujkovic M, Travas-Sejdic J, Ciric-Marjanovic G, Mentus SV. High-performance charge storage by N-containing nanostructured carbon derived from polyaniline. Carbon 2012; 50: 3915-27.

[70] Wu C, Wang X, Ju B, Jiang L, Wu H, Zhao Q, Yi L. Supercapacitive performance of nitrogen-enriched carbons from carbonization of polyaniline/activated mesocarbon microbeads. J Power Sources 2013; 227: 1-7.

[71] Wang C, Sun L, Zhou Y, Wan P, Zhang X, Qiu J. P/N co-doped microporous carbons from $\mathrm{H}_{3} \mathrm{PO}_{4}$-doped polyaniline by in situ activation for supercapacitors. Carbon 2013; 59: 537-46.

[72] Su F, Poh CK, Chen JS, Xu G, Wang D, Li Q, Lin J, Lou XW. Nitrogen-containing microporous carbon nanospheres with improved capacitive properties. Energy Environ Sci 2011; 4: 717-24.

[73] Conway BE. Electrochemical supercapacitors: Scientific fundamentals and technological applications, New York: Plenum Press; 1999.

[74] Wu X, Xing W, Florek J, Zhou J, Wang G, Zhuo S, Xue Q, Yan Z, Kleitz F. On the origin of the high capacitance of carbon derived from seaweed with an apparently low surface area. J Mater Chem A 2014; 2: 18998-19004.

[75] Wu X, Zhou J, Xing W, Zhang Y, Bai P, Xu B, Zhuo S, Xue Q, Yan Z. Insight into high areal capacitances of low apparent surface area carbons derived from nitrogen-rich polymers. Carbon 2015; 94: 560-7.

[76] Lozano-Castelló D, Cazorla-Amorós D, Linares-Solano A. Usefulness of $\mathrm{CO}_{2}$ adsorption at $273 \mathrm{~K}$ for the characterization of porous carbons. Carbon 2004; 42: 1233 42. 
[77] Guillot A, Stoeckli F. Reference isotherm for high pressure adsorption of $\mathrm{CO}_{2}$ by carbons at 273 K. Carbon 2001; 39: 2059-64.

[78] Stoeckli F, Guillot A, Slasli AM, Hugi-Cleary D. The comparison of experimental and calculated pore size distributions of activated carbons. Carbon 2002; 40: 383-8.

[79] Stoeckli F, Slasli A, Hugi-Cleary D, Guillot A. The characterization of microporosity in carbons with molecular sieve effects. Micropor Mesopor Mat 2002; 51: 197-202.

[80] Pohlmann S, Lobato B, Centeno TA, Balducci A. The influence of pore size and surface area of activated carbons on the performance of ionic liquid based supercapacitors. Phys Chem Chem Phys 2013; 15: 17287-94.

[81] Ravikovitch PI, Vishniakov A, Russo R, Neimark AV. Unified approach to pore size characterization of microporous carbonaceous materials from $\mathrm{N}_{2}$, Ar and $\mathrm{CO}_{2}$ adsorption isotherms. Langmuir 2000; 16: 2311-20.

[82] Neimark AV, Lin Y, Ravikovitch PI, Thommes M. Quenched solid density functional theory and pore size analysis of micro-mesoporous carbons. Carbon 2009; 47: $1617-28$.

[83] Barranco V, Garcia-Gomez A, Kunowsky M, Linares-Solano, Ibañez J, King M, Rojo JM. The contribution of sulfate ions and protons to the specific capacitance of microporous carbon monoliths. J Power Sources 2014; 262: 23-8.

[84] Jäckel N, Simon P, Gogotsi Y, Presser V. Increase in capacitance by subnanometer pores in carbon. ACS Energy Lett 2016; 1: 1262-5.

[85] Jäckel N, Rodner M, Schreiber A, Jeongwook J, Zeiger M, Aslan M, Weingarth D, Presser V. Anomalous or regular capacitance? The influence of pore size dispersity on double-layer formation. J Power Sources 2016; 326: 660-71.

[86] Caguiat JN, Kirk DW, Jia CQ. Uncertainties in characterization of nanoporous carbons using density functional theory-based gas physisorption. Carbon 2014; 72: 47 56.

[87] Stoeckli F, Centeno TA. On the characterization of microporous carbons by immersion calorimetry alone. Carbon 1997; 35: 1097-1100.

[88] Gu W, Yushin G. Review of nanostructured carbon materials for electrochemical capacitor applications: advantages and limitations of activated carbon, carbide-derived carbon, zeolite-templated carbon, carbon aerogels, carbon nanotubes, onion-like carbon, and graphene. WIREs Energy Environ 2014; 3: 424-73. 
[89] Feng Z, Xue R, Shao X. Highly mesoporous carbonaceous material of activated carbon beads for electric double layer capacitor. Electrochim Acta 2010; 5: 7334-40.

[90] Jiang D, Jin Z, Henderson D, Wu J. Solvent effect on the pore-size dependence of an organic electrolyte supercapacitor. J Phys Chem Lett 2012; 3: 1727-31.

[91] Jiang D, Wu J. Unusual effects of solvent polarity on capacitance for organic electrolytes in a nanoporous electrode. Nanoscale 2014; 6: 5545-50.

[92] Hsieh W, Allen Horng TL, Huang HC, Teng H. Facile simulation of carbon with wide pore size distribution for electric double-layer capacitance based on Helmholtz models. J Mater Chem A 2015; 3: 16535-43.

[93] Garcia-Gómez A, Barranco V, Moreno-Fernández G, Ibáñez J, Centeno TA, Rojo JM. Correlation between capacitance and porosity in microporous carbon monoliths. J Phys Chem C 2014; 118: 5134-41.

[94] Decaux C, Matei Ghimbeu C, Dahbi M, Anouti M, Lemordant D, Béguin F, VixGuterl C, Raymundo-Piñero E. Influence of electrolyte ion-solvent interactions on the performances of supercapacitors porous carbon electrodes. J Power Sources 2014; 263: $130-40$.

[95] Kleszyk P, Ratajczak P, Skowron P, Jagiello J, Abbas Q, Frackowiak E, Béguin F. Carbons with narrow pore size distribution prepared by simultaneous carbonization and self-activation of tobacco stems and their application to supercapacitors. Carbon 2015; 81: 148-57.

[96] Yamada H, Moriguchi I, Kudo T. Electric double layer capacitance on hierarchical porous carbons in an organic electrolyte. J Power Sources 2008; 175: 651-6.

[97] Conceiçao FL, Carrott PJM, Ribeiro Carrott MML. New carbon materials with high porosity in the 1-7 nm range obtained by chemical activation with phosphoric acid of resorcinol-formaldehyde aerogels. Carbon 2009; 47: 1867-85.

[98] Jin J, Tanaka S, Egashira Y, Nishiyama N. KOH activation of ordered mesoporous carbons prepared by a soft-templating method and their enhanced electrochemical properties. Carbon 2010; 48: 1985-9.

[99] Morishita T, Tsumura T, Toyoda M, Przepiórski J, Morawski AW, Konno H, Inagaki $\mathrm{M}$. A review of the control of pore structure in MgO-templated nanoporous carbons. Carbon 2010; 48: 2690-707.

[100] Centeno TA, Sevilla M, Fuertes AB, Stoeckli F. On the electrical double-layer capacitance of mesoporous templated carbons. Carbon 2005; 43: 3012-5. 
[101] McDonough JK, Gogotsi Y. Carbon onions: Synthesis and electrochemical applications. Electrochem Soc Interface 2013;2: 61-6.

[102] Huang Y, Liang J, Chen Y. An overview of the applications of graphene-based materials in supercapacitorS. Small 2012; 8: 1805-34.

[103] Randviir EP, Brownson DAC, Banks CE. A decade of graphene research: production, applications and outlook. Mater Today 2014; 17:426-32.

[104] Zhang X, Zhang H, Li C, Wang K, Sun X, Ma Y. Recent advances in porous graphene materials for supercapacitor applications. RSC Adv 2014; 4: 45862-84.

[105] Ke Q, Wang J. Graphene-based materials for supercapacitor electrodes: A review. J Materiomics 2016; 2: 37-54.

[106] Raccichini R, Varzi A, Passerini S, Scrosati B. The role of graphene for electrochemical energy storage. Nat Mater 2015; 14:271-9.

[107] Ren W, Cheng HM. The global growth of graphene. Nat Nanotechnol 2014; 9: 726-30.

[108] Zurutuza A, Marinelli C. Challenges and opportunities in graphene commercialization. Nat Nanotechnol 2014; 9; 730-4.

[109] Zhong YL, Tian Z, Simon GP, Li D. Scalable production of graphene via wet chemistry: progress and challenges. Mater Today 2015; 18: 73-8.

[110] Stoller MD, Park SJ, Zhu YW, An JH, Ruoff RS. Graphene-based ultracapacitors. Nano Lett 2008; 8: 3498-502.

[111] Du Q, Zheng M, Zhang L, Wang Y, Chen J, Xue L, Dai W, Ji G, Cao J. Preparation of functionalized graphene sheets by a low-temperature thermal exfoliation approach and their electrochemical supercapacitive behaviors. Electrochim Acta 2010; 55: 3897-03

[112] Lv W, Tang DM, He YB, You CH, Shi ZQ, Chen XC, Chen CM, Hou PX, Liu C, Yang QH. Low-temperature exfoliated graphenes: Vacuum-promoted exfoliation and electrochemical energy storage. ACS Nano 2009; 3: 3730-6.

[113] Zhu Y, Murali S, Stoller MD, Velamakanni A, Piner RD, Ruoff RS. Microwave assisted exfoliation and reduction of graphite oxide for ultracapacitors. Carbon 2010; 48: $2118-22$.

[114] Zhu Y, Murali S, Stoller MD, Ganesh KJ, Cai W, Ferreira PJ, Pirkle A, Wallace RM, Cychosz KA, Thommes M, Su D, Stach EA, Ruoff RS. Carbon-based supercapacitors produced by activation of graphene. Science 2011; 332: 1537-41. 
[115] Buglione L, Chng ELK, Ambrosi A, Sofer Z, Pumera M. Graphene materials preparation methods have dramatic influence upon their capacitance. Electrochem Commun 2012; 14: 5-8.

[116] Song W, Ji X, Deng W, Chen Q, Shen C, Banks CE. Graphene ultracapacitors: structural impacts. Phys Chem Chem Phys 2013; 15: 4799-803.

[117] Stoller MD, Magnuson CW, Zhu Y, Murali S, Suk JW, Piner R, Ruoff RS. Interfacial capacitance of single layer graphene. Energy Environ Sci 2011; 4: 4685-9.

[118] Zhang LL, Zhao X, Ji H, Stoller MD, Lai L, Murali S, Mcdonnell S, Cleveger B, Wallace RM, Ruoff RS. Nitrogen doping of graphene and its effect on quantum capacitance, and a new insight on the enhanced capacitance of N-doped carbon. Energy Environ Sci 2012; 5: 9618-25.

[119] Droscher PRS, Molitor F, Studerus P, Stampfer C, Ensslin K, Ihn T. Quantum capacitance and density of states of graphene. Appl Phys Lett 2010; 96: 152104-6.

[120] Fang T, Konar A, Xing H, Jena D. Carrier statistics and quantum capacitance of graphene sheets and ribbons. Appl Phys Lett 2007; 91: 092109.

[121] Sahu V, Shekhar S, Sharma RK, Singh G. Ultrahigh Performance Supercapacitor from Lacey Reduced Graphene Oxide Nanoribbons. ACS Appl Mater Interfaces 2015; 7: 3110-6.

[122] Hantel MM, Kaspar T, Nesper R, Wokaun A, Kötz R. Partially reduced graphite oxide for supercapacitor electrodes: Effect of graphene layer spacing and huge specific capacitance. Electrochem Commun 2011; 13: 90-2.

[123] Mitani S, Sathish M, Rangappa D, Unemoto A, Tomai T, Honma I. Nanographene derived from carbon nanofiber and its application to electric double-layer capacitors. Electrochim Acta 2012; 68: 146-52.

[124] Hao J, Liao Y, Zhong Y, Shu D, He C, Guo S, Huang Y, Zhong J, Hu L. Threedimensional graphene layers prepared by a gas-foaming method for supercapacitor applications. Carbon 2015; 94: 879-87.

[125] Cheng Q, Tang J, Ma J, Zhang H, Shinya N, Qinc LC. Graphene and carbon nanotube composite electrodes for supercapacitors with ultra-high energy density. Phys Chem Chem Phys 2011; 13: 17615-24.

[126] Abbas Q, Pajak D, Frackowiak E, Béguin F. Effect of binder on the performance of carbon/carbon symmetric capacitors in salt aqueous electrolyte. Electrochim Acta 2014; 140: 132-8. 